\title{
Reflexão da prática docente no ambiente escolar: Um diálogo singular necessário sob o olhar do educando de Química na Educação Básica
}

\author{
Reflecting on teaching practice in the school environment: A necessary singular dialogue from the \\ perspective of the chemistry student in Basic Education \\ Reflexión de la práctica docente en el ámbito escolar: Un diálogo singular necesario desde la \\ perspectiva del estudiante de química en la Educación Básica
}

\section{Resumo}

No movimento do vai e vêm do ambiente escolar, na figura do docente é preciso entrelaçar os caminhos que levam cada um a uma aprendizagem, nesse cenário é preciso ter um olhar singular, possibilitar no outro uma condição de transformação. Portanto ao discorrer sobre o Ensino de Química nos esbarramos em limites que muitas vezes surgem do próprio conteúdo, existe uma certa necessidade de levar ao próximo aquilo que é dele por direito que é o conhecimento. Mas muitas vezes esquecemos que por trás do aluno, existe um sujeito que muitas vezes se encontra fisicamente no espaço escolar, mas ao mesmo tempo seus pensamentos transitam por outros problemas, muitos deles advindos das relações familiares, no âmbito social. Esse artigo objetiva entrelaçar as relações cotidianas construídas entre o professor de Química e os alunos de uma turma da $1^{a}$ série do ensino médio, em uma escola da rede pública estadual de ensino no município de Nova Venécia, Es, a partir do momento que se enxerga a dificuldade dos alunos em compreender o conteúdo de Química, mediante a isso intensifica a necessidade de refletir que antes de mais nada tornase necessário enxergar e entender os alunos nas suas relações com o mundo. Desta forma com referência as reflexões que foram aos poucos sendo construídas, discute e ao mesmo tempo conclui a importância de enxergar o aluno dentro de suas potencialidades, mediante um processo de interação que é fundamental para a construção de um ambiente que prioriza o processo de ensino e aprendizagem.

Palavras-chave: Ensino de química; Relações cotidianas; Ensino e aprendizagem.

\begin{abstract}
In the movement back and forth of the school environment, in the figure of the teacher it is necessary to interweave the paths that lead each one to learning, in this scenario it is necessary to have a unique look, to enable in the other a condition of transformation. Therefore, when discussing the teaching of chemistry, we come up against limits that often arise from the content itself; there is a certain need to bring to others what is rightfully theirs, which is knowledge. But we often forget that behind the student, there is a subject who is often physically in the school space, but at the same time his thoughts go through other problems, many of them arising from family relationships in the social environment. This article aims to interweave the daily relationships built between the chemistry teacher and the students of a 1st grade class in a public school in the municipality of Nova Venécia, Es, from the moment that we see the difficulty of students in understanding the content of chemistry, through this intensifies the need to reflect that first of all it becomes necessary to see and understand the students in their relationships with the world. Thus with reference to the reflections that were gradually being built, discusses and at the same time concludes the importance of seeing the student within their
\end{abstract}


potential, through a process of interaction that is fundamental to building an environment that prioritizes the process of teaching and learning.

Keywords: Chemistry teaching; Everyday relationships; Teaching and learning.

\section{Resumen}

En el movimiento de ida y vuelta del entorno escolar, en la figura del profesor, es necesario entrelazar los caminos que llevan a cada uno al aprendizaje, en este escenario es necesario tener una mirada única, para posibilitar en el otro una condición de transformación. Por lo tanto, al hablar de la enseñanza de la química nos encontramos con límites que a menudo surgen del propio contenido, hay una cierta necesidad de aportar a los demás lo que les corresponde, que es el conocimiento. Pero a menudo olvidamos que detrás del alumno hay un sujeto que suele estar físicamente en el espacio escolar, pero al mismo tiempo sus pensamientos pasan por otros problemas, muchos de ellos derivados de las relaciones familiares en el ámbito social. Este artículo pretende entrelazar las relaciones cotidianas construidas entre el profesor de química y los alumnos de una clase de $1^{\circ}$ de bachillerato, en una escuela de la red pública de enseñanza estatal en el municipio de Nova Venécia, Es, desde el momento en que se ve la dificultad de los alumnos para comprender el contenido de la química, a través de esto se intensifica la necesidad de reflexionar que en primer lugar se hace necesario ver y comprender a los alumnos en sus relaciones con el mundo. Así con referencia a las reflexiones que se fueron construyendo, discute y a la vez concluye la importancia de ver al alumno dentro de sus potencialidades, a través de un proceso de interacción que es fundamental para la construcción de un ambiente que priorice el proceso de enseñanza y aprendizaje.

Palabras clave: Enseñanza de la química; Relaciones cotidianas; Enseñanza y aprendizaje.

\section{Introdução}

O ambiente escolar por mais dinâmico que possa ser, apresenta uma complexidade de relações muito grande (Galiazzi, 2003). Entender a forma de pensar, aprender e socializar de cada um que ali permanece parte do seu dia, é criar oportunidades para um crescimento mais produtivo.

Segundo Machado (2004), os conhecimentos produzidos em relação ao Ensino de Química muitas vezes podem ser pequenos comparados aos problemas que muitos alunos trazem do seu convívio social. Desta forma, a partir da visão que se cria sobre o educando em relação as singularidades estabelecidas na relações professor-aluno, é que se possibilita discutir e entender que o ensino mediado em sala de aula muitas vezes está além dele.

Nessa perspectiva Moura e Guerra (2016) colocam que o ensino por mais dinâmico que seja, reflete muitas vezes uma realidade não tão verdadeira. Com isso, o que estão por trás dos índices que a escola alcança nas avaliações? Durante a prática docente em sala de aula, aos poucos foi percebendo por parte do educador a repetição do mesmo diálogo com os alunos: "Boa tarde turma, como vão vocês?", logo em seguida se destinava ao quadro branco, datava e colocava a reflexão: “foco e determinação”, virava novamente para os alunos e iniciava a minha aula. Nesse movimento em sala de aula, certa vez os alunos questionaram sobre o que me motivava a escrever aquilo, e sinceramente não tinha uma resposta pronta, nunca havia pensado no porquê, entretanto de alguma forma esse momento era necessário.

Cada dia da semana ao ter contato com as turmas, surgiam os mesmos problemas, tais como conversas paralelas e desinteresse. De certa forma, esse reflexo frustra o educador, a partir desses momentos vivenciados que surgem uma reflexão e ao mesmo tempo uma indagação: Como exigir tanto dos alunos, se não os conheço como sujeitos? Tal indagação surge a partir do momento que existe uma certa necessidade de se reinventar em sala de aula, assim pontuava: "na próxima aula vou levar algo diferente", no qual a maior parte dos alunos adoravam, embora nem todos participavam. Todavia, existe esse pensar que se uma maioria fosse participa, revela que de fato a aula segue por um caminho correto, mas e aquele aluno que não participava? Existia um olhar diferenciado para ele?

Ao retomar a fala inicial de todas a aulas: "Boa tarde turma, como vão vocês?”, por que não dar a oportunidade de escutar verdadeiramente os alunos, ao invés de logo virar para o quadro branco. E aquele aluno que de alguma forma não quer participar da aula seja lá qual foi o motivo, por que ao menos em algum momento da aula não conversar com ele, e entender de fato a sua justificativa? 
A partir desses pontos de discussão, o presente trabalho objetiva propor uma indagação e reflexão sobre quem são os alunos no ambiente escolar, e para além da sala de aula, tais questão surgem a partir do momento que se enxerga a dificuldade dos alunos em compreender o conteúdo de Química. Assim, o artigo busca refletir que antes de mais nada, essa preocupação de entender o outro torna-se necessário para entender suas relações com o mundo.

Todos discursos apresentados, surgem em decorrência do convívio em sala de aula e do ambiente escolar, juntamente com os alunos da $1^{\text {a }}$ série do Ensino Médio, em uma escola da Rede Pública Estadual de Ensino no município de Nova VenéciaEspírito Santo (ES), mediante as relações construídas na disciplina de Química.

Esse trabalho configura o educando como ponto central na construção do texto, apresentando algumas considerações sobre como eles deveriam ser vistos no ambiente escolar e como o conhecimento Químico se desenvolve nesses espaços. Além de estender para um olhar reflexivo sobre a sala de aula, uma vez que sem a presença dos alunos nesse espaço, não passa de apenas um cômodo vazio como tantas outras construções. Os diálogos ao longo da pesquisa discutem a constituição dos processos coletivos, que são reflexos da importância da articulação entre educando e educador no processo de Ensino e Aprendizagem, elucidados na perspectiva histórico-cultural de Vygotsky (2007, 2000).

\section{Metodologia}

Este estudo decorreu de uma pesquisa qualitativa que propõe um contato direto e longo do pesquisador com o seu objeto de estudo, pensando que este último é influenciado pelo seu contexto e, para entendê-lo é necessário observar e analisar o meio em que o mesmo está inserido, para valorizar o processo em detrimento do fim evidenciando a visão do sujeito participante (Ludke \& André, 2014).

A abordagem metodológica utilizada serão os comportamentos e narrativas, como enfoque na observação. Um trabalho de observação exige dois pontos: a descrição e a reflexão. A primeira contempla o registro detalhado do que ocorre no campo, e a segunda envolve as observações pessoais do pesquisador. Estes pontos estão relacionados com o foco de observação do trabalho (Ludke \& André,2014). As reflexões tecidas surgem mediante o primeiro ano de docência na Educação Básica, de um professor de Química, envolvendo 24 alunos da $1^{\text {a }}$ série do Ensino Médio em uma escola da rede estadual de ensino no município de Nova Venécia, no estado do Espírito Santo.

Mediante a imersão dos resultados obtidos em decorrência desse processo de interação com o outro, e a partir dessa etapa de observação, surgem três tópicos que transpõe a perspectiva do sujeito envolvido a partir desse convívio com o outro intitulado: i) "Tecendo reflexões com os discentes no que tange sua constituição histórica e social"; ii) "Ampliando o olhar a partir do conhecimento de Química no ambiente escolar"; iii) "Como me moldo em virtude do outro? Uma reflexão necessária". Os três capítulos dialogam na necessidade de ampliar o olhar para a construção do processo de ensino e aprendizagem, que por muitas vezes se encontra engessado no campo educacional, e principalmente a necessidade de ampliar o olhar voltado para os sujeitos no ambiente escolar.

\section{Resultados e Discussão}

\subsection{Tecendo reflexões com os discentes no que tange sua constituição histórica e social}

Sempre no início de um ano letivo, existe a ansiedade em saber quem serão os novos alunos, e quando chega esse dia tem aquela apresentação e as horas rapidamente passam. As próximas aulas das semanas seguintes serão apenas mais uma, que irão compor ao todo 200 dias letivos. Com o passar do tempo, a percepção que se obtém é que existe a necessidade de ter um olhar singular para cada educando, pois diferentes histórias permeiam a sala de aula, devendo ser incluídas nos processos de aprendizagem. 
Desta forma, faz-se necessária uma aproximação maior do educando, no sentido de que somos seres diferentes e nos constituímos nas relações desenvolvida com o outro (Carvalho, 1988). Por outro lado, esse tópico propõe a refletir: Será que o aluno vê o professor para além da sua profissão? Para esse questionamento, necessita antes de mais nada o educador repensar as suas próprias atitudes cotidianas.

Ao entrar na sala de aula, a presença do docente pode intimidar ou fazer nenhuma diferença. Muitos docentes são “queridos" pelos educandos e outros nem tanto. Muitas vezes o que se percebe é que embora o planejamento da aula segundo a visão do professor seja o modelo ideal, muitas vezes a devolutiva que se tem é uma falta de interesse em aprender com relação ao discente, o que acarreta em uma frustração, impactando diretamente na prática pedagógica em sala.

A partir do momento que se enxerga um aluno como um indivíduo, a compreensão na forma de interpretar as suas atitudes muda literalmente (Maia \& Justiz, 2008). Existe tantos problemas nesse espaço que estão além da resolução de exercícios, muitas vezes o educando está tão longe da sala de aula, mesmo que esteja ali pessoalmente.

É justamente neste ponto que Vygotsky (2000) se apoia para tecer suas reflexões que norteiam a necessidade dessa aproximação entre professor e aluno como sujeitos historicamente constituídos. Assim, é decorrente desse processo gradativo de convivência do "eu" com o "outro" mediante a evolução das funções psicológicas. Na qual se desenvolve diretamente nas relações pessoais e à medida que são internalizadas e significadas, que conseguimos ampliar nosso olhar para o outro. Desta forma, refletindo a partir disso, foi possível perceber que os fatores externos afetam diretamente na forma como o discente se desenvolve no ambiente escolar.

Como ensinar sobre ligações químicas, conceituando as diferenças entre ligação iônica, covalente e metálica, se quando o aluno chega sem sala de aula, a vida social se encontra com tantas barreiras que a mente se fecha apenas para isso. É fácil associar a palavra “desinteresse", simplesmente porque o indivíduo X não copia as atividades, ou o indivíduo Y não quer nem ouvir o que o professor está explicando. É possível afirmar que essa sensibilidade não se reflete a todos os casos, mas quando se começa a perceber que o papel do docente está além da disciplina que leciona, é a partir desse contraponto que conheço melhor cada turma e principalmente o verdadeiro papel como educador.

Mediante uma reflexão feita ao longo dos dias letivos na sala de aula, identificou-se que entre o quadro branco e os alunos, tem o professor, e essa diferença que embora seja pequena, reflete nas suas relações com a turma. Ou seja, a partir do momento que a atenção se volta mais para o educando e não apenas para o quadro branco, as relações se tecem de modo mais produtivo.

Em uma aula que dura 55 minutos, é muito difícil que a atenção do aluno se foque 100\% na figura do docente e seu conteúdo em si. Desta forma, o uso do diálogo e a comunicação se apresentam como uma ferramenta que potencializa as relações cotidianas. Nesse sentido, o ato de educar é um ato de comunicação (Freire, 1976). Ao invés de apenas perguntar, "boa tarde, como vocês vão?" e se fechar para a aula em si, é necessário dar um tempo, parar e ouvir as respostas dos educandos, para só a partir de então estabelecer os diálogos da disciplina, e quem sabe tecer discussões contextualizadas com o cotidiano relado pelos alunos.

A partir da convivência tanto em sala de aula como fora dela, foi nítido perceber o quanto alguns alunos são carentes de atenção. Nessa perspectiva, infere-se que o meio o qual estava inserido, influenciava nas minhas relações com a turma. Logo, quando se permite ouvir mais, observar mais, e fazer uma verdadeira reflexão, é que nos reconstituímos como professor (Freire, 1976; Vygotsky, 2000).

Nesse cenário, Vygotsky (2000) discorre que para que os conceitos se fundamentem, é necessário que o pensamento abstrato também se desenvolva. Assim, em sala de aula devemos analisar os processos e como as aprendizagens acontecem ao longo deles. Por isso, os debates voltados para esses espaços são fundamentais, por mais que o aluno não desenvolva no mesmo ritmo um conhecimento estritamente científico das aprendizagens cotidianas, mediadas pelo professor, é preciso refletir que 
alguns momentos os saberes adquiridos estão o constituindo internamente, e isso o docente não enxerga apenas percebe quando dá espaço para ouvir os alunos.

Portanto, a aprendizagem está no processo de apropriação de um determinado conhecimento a todo instante (Moreira, 2017), e isso varia para cada aluno, pois as suas relações familiares e escolares impactam diretamente na relação com o professor. Em virtude disso, é fácil estabelecer relações com o educando quando reconhecemos quem somos e como agimos. Logo, devemos reconhecer que o aluno se constitui dentro das escolas e principalmente fora do âmbito escolar.

\subsection{Ampliando o olhar a partir do conhecimento de Química no ambiente escolar}

Quando questionamos os alunos o que entendem sobre a definição de um ácido, a resposta vem associada a um exemplo, "o ácido vem do limão". O que se deve avaliar nesse conhecimento mediado, é como o aluno tem a capacidade de fazer associações, e aplica-las dentro do conhecimento científico (Chassot, 2002; Silva et al, 2021). Nesse contexto a turma toda se embala por essa resposta e sugere outras da mesma linha de raciocínio: "que ácido pode vir da laranja, mexerica, também”. De fato, a resposta cientificamente não é essa, mas todos eles entenderam que o termo ácido, está presente na sua prática cotidiana. Por isso há uma necessidade da sistematização do saber que deve ser mediado em sala de aula (Moreira, 2017).

Por mais abstrato que seja o Ensino de Química (EQ), umas das suas grandes dificuldades se fundamenta na concepção de que é necessário aprender de qualquer forma um determinado conceito associado ao conteúdo. Mas de fato, torna-se tão difícil essa cobrança, uma vez que para o professor a formulação de diversos conceitos foram sendo construídos e se constituído ao longo da sua graduação e experiência profissional (Harres, 1999). Assim, é necessário refletir que cada aluno tem a sua peculiaridade e aprende de formas completamente diferentes, como pontuado por Ramos e Moraes (2011) discutem

[...] Nesse caso o professor, como detentor de um discurso químico e científico mais complexo, contribui e enriquece o diálogo em busca dessa maior diversificação. Para o aluno, no entanto, em geral essa busca de compreensão supera os limites da disciplina, mesmo porque ele não conhece esses limites (p. 315).

A relação entre o conhecimento do professor e do aluno, são pilares que se fortificam nas suas relações em sala de aula e no ambiente escolar (Maldaner, 2007), nesse sentido, a aprendizagem está muito além receber e escrever informações de forma mecanizada. Por isso, o modo como o docente quer ensinar deve ampliar o significado de algo já conhecido pelo discente.

Durante o convívio em sala de aula, as expressões que os educandos fazem com relação a determinados conteúdos são uma dica ideal para orientar o docente com relação ao que está sendo desenvolvido atinge esse aluno. As vezes no mesmo instante é preciso repensar outros caminhos de aprendizagens mais rápidos e acessíveis. Para tanto, o ambiente "sala de aula" é muito imprevisível nesse sentido. Maldaner (2007) discorre que as respostas a diferentes abordagens nem sempre apresentam os mesmos resultados, alguns conteúdos são associados com muita facilidade, e outros nem tanto.

Muitas vezes o questionamento feito pelos alunos permeia sempre a mesma problemática: "porque eи tenho que aprender isso?". Essa indagação é carregada de tanto significado que dependendo da devolutiva por parte do professor, gera uma falta de interesse ainda maior no aluno. Pensando assim, devemos partir da premissa de que quanto mais conhecimento construído, mais se desenvolve o sujeito (Vygotsky, 2007). O aprendizado está muito à frente da escola, no entanto o aluno não tem essa sensibilidade de associar que para o seu crescimento pessoal essa percepção não se fundamenta. Como pontua Moreira (2017), um processo deve delinear aprendizagens que são mediadas a curto prazo de tempo, mas que para a vida vão ser representativas em algum momento.

Quando analisamos a formação e permanência das ideias prévias que os educandos possuem, é necessário que se compreenda sua constituição histórico-cultural, uma vez que isso está diretamente relacionado aos processos cognitivos na 
formação dos conceitos cotidianos, quanto na formação dos conceitos científicos (Maldaner, 2013). Por isso, a necessidade de resgatar os discursos manifestados a partir do seu convívio social e relacionar as concepções científicas.

Com base nisso, Vygotsky (2000) discorre que as relações que internalizamos geram aprendizagem, e o cultural vai se inserindo no sujeito biológico essas modificações. Assim, para entender as defasagens dos alunos em sala de aula, é preciso que discuta o pensamento e a linguagem que compõem esse sujeito, e que cada palavra carrega um sentido, conceito e significado.

O Conteúdo Básico Comum do Espírito Santo (CBC/ES) (Espírito Santo, 2009), discute em seu tópico sobre "diversidade na formação humana", que todo o aluno se desenvolve de forma diferente, e é isso que torna a educação tão desafiadora e ao mesmo tempo fascinante.

Alguns questionamentos são levantados pelo CBC/ES (Espírito Santo, 2009), a respeito da prática pedagógica dos professores:

Como eu, professor, estou desafiando meus alunos, propondo atividades que oportunizem a aprendizagem? Quais estratégias estou utilizando para que meus alunos desenvolvam competências e habilidades que o possibilitem resolver situações-problema, com tomada de decisão? (p. 45).

Deste modo, as reflexões estabelecidas com relação ao EQ, expressam que a construção ou até mesma a reconstrução de um conhecimento químico em sala de aula deve discutir a natureza do conhecimento científico e sua relação com a sociedade (Gil-Perez et al, 2001; Mccmas; Clough; Nouri, 2019; Gomes, 2020). Com isso, a relação que se cria entre os saberes que os alunos possuem advindos nas suas interações fora do ambiente escolar e aquele que o professor media, são meios facilitadores de uma aprendizagem, assim é necessário "refletir sobre a construção ou a reconstrução do conhecimento químico junto aos adolescentes e aos jovens, discutir a natureza do conhecimento científico e seu significado na sociedade atual [...]" (Maldaner, 2013, p. 205).

Contribuindo com essa discussão, Schnetzler (2002) justifica que a organização conceitual deve estar vinculada com articulações teórico-práticas, que são questões mais adequadas a uma aprendizagem. Sendo assim, o professor em sala de aula deve desenvolver o seu papel de mediador, e propor metodologias que proporcionem ao educando contemplar outras formas de aprender.

O ensino que se restringe apenas na parte quantitativa, traduz somente dados estatísticos sendo um processo rápido e muitas vezes falho. A avaliação de modo qualitativo vem a ser um processo de aprendizagem mais lento, entretanto traz mais significado para o aluno.

Em uma experiência vivenciada com a turma da $1^{\text {a }}$ série, os alunos foram orientados a pesquisar sobre atividades experimentais que pudessem ser realizadas em sala de aula, com relação ao conteúdo de funções inorgânicas. A sala foi disposta em grupos, e um aluno de um determinado grupo não conseguiu encontram nada. A mediação orientada foi que ele pensasse no trajeto de sua casa até a escola, o que ele poderia associar nesse percurso com possibilidades de envolver o assunto solicitado.

Foi a partir disso que surgiram outras possibilidades para esse aluno. Por ser uma escola do interior, a maioria dos discentes tem mais facilidade em compreender alguns processos associados ao campo, uma vez que está inserido a sua rotina. Esse aluno mencionava que umas das coisas que ele fazia, era jogar calcário na terra para corrigir a acidez do solo. Novamente foi questionado como que ele aferia acidez do solo, e com toda a sutileza explicou o procedimento: "A amostra do solo tem que ser retirada a $30 \mathrm{~cm}$ abaixo do solo, depois que faz isso, coloca na máquina e ver o valor que dá".

A utilização da frase "acidez dos solos" e "amostra do solo" relatado, reflete que esse educando usa termos diretamente relacionadas a análises experimentais. Esse conhecimento que possui, embora que para ele não representa muita coisa, pois era 
algo rotineiro das suas experiências cotidianas, reflete que o desenvolvimento da aprendizagem química, permeia por várias vias, direta ou indiretamente.

Em conclusão a esse fato, o educando se interessou a pesquisar novas formas de medir a acidez do solo, embora como docente reconhecia que existe vários meios experimentais, não poderia ofuscar a vontade dele em pesquisar. Uma devolutiva que com base nesse discurso, foi o fato do docente não saber porque era necessário retirar a amostra de solo a $30 \mathrm{~cm}$ abaixo do solo, sendo que em algumas literaturas mencionam $10 \mathrm{~cm}$. Mas o fato, é que esses saberes foram adquiridos nas suas relações cotidianas fora do ambiente escolar.

Desta forma, avaliar realmente quem aprende Química é observar nas sutilezas dos discursos, dando mais voz aos educandos. No entanto, é claro que a necessidade do conhecimento científico também é importante, e o desenvolvimento de outras percepções sejam na escrita quanto na linguagem, também são fundamentais, e a partir disso criar possibilidades para que eles percebam que nem tudo está fora do seu alcance.

\subsection{Como me moldo em virtude do outro? Uma reflexão necessária}

A discussão fundamentada até aqui, se alinha na convivência em sala de aula, uma vez que é através do outro que nos constituímos. A partir do momento que se percebe que o meio a qual estamos inseridos aos poucos muda a nossa concepção em sala de aula, percebemos que para ser professor é necessário se posicionar muito além de apenas ministrar conteúdos, mas sim, na possibilidade criar pontes e ser o mediador de sonhos.

Embora se tenha a noção que para ser professor é preciso se reinventar nas suas relações, até entender isso na prática, é completamente diferente e complexo. $\mathrm{O}$ fato de dar um bom dia ou boa tarde, e se virar para os alunos e realmente compreender quem eles são, foi e sempre será desafiador, no sentido de ter que ministrar conteúdos e ao mesmo tempo criar essas relações que de certo modo são saudáveis em sala de aula. E nesse cenário aos poucos se percebe que as relações estabelecidas com as turmas vão sendo constituídas além da disciplina de Química.

Para que eles pudessem me perceber não apenas como professor tive que me permitir a interagir mais. Nesse formato, o que se pode afirmar é que essa dialética prioriza me constituir através dos outros e eles se constituem através de mim (Vygotsky, 2007). Por isso, antes de mediar o conhecimento químico, será necessário romper a barreira entre professor e aluno que gera uma hierarquia educacional. Parafraseando esse discurso com Serpa et. al (2021)

O saber está relacionado e comprometido com a prática. Prática essa que está comprometida também com a cultura na qual o indivíduo está inserido (do grupo da qual faz parte) e com as necessidades socioeconômicas desse grupo. Mas para o aparecimento e consolidação desse ideal de organicidade entre teoria e prática é necessário que adentremos uma questão fundamental para o caminho traçado por uma sociedade: a educação (p.3).

Desta forma, foi possível perceber que primeiro existe essa necessidade de entender quem são meus alunos, e a partir disso internalizar essas relações e as significar juntamente com os discentes. O conteúdo em sala de aula é importante, apresentar ao educando que a Química está na sua casa, ou no seu percurso até a escola, é fantástico. Isso nos mostra que é ao longo da internalização do processo de conhecimento que vem a ocorrer a construção da aprendizagem.

\section{Conclusão}

No início desse trabalho me propus tecer algumas considerações sobre o ensino de química, buscando encontrar nas minhas falas a Química das salas de aula, descontextualizada e difícil compreensão. Dessa forma, o que se percebe, é que muitas vezes a questão da prática profissional do professor é vista por ele como essencialmente simples, onde basta saber alguns conteúdos e passá-los aos alunos para que devolvam da maneira como ele pede, sem levar em consideração os pensamentos 
externos trazidos pelos alunos em sala de aula. Com isso, a relação professor-aluno vem a se resumir estritamente dentro do âmbito escolar.

Entretanto, é necessário elaborar e implementar uma proposta para o Ensino da Química mais coerente com as necessidades reais dos alunos, incluindo os mesmos neste processo. Uma proposta problematizadora e atuante no meio e que, também, considere o aluno além de um sujeito possuidor de um conhecimento, e que traz consigo diversas vivências do seu cotidiano, vem a ser um componente essencial dos processos de ensino e aprendizagem. Pode ser bom ou ruim, mas o professor não deve negligenciar o que é trazido pelo educando nesse processo, sejam problemas, emoções, dificuldades, etc.

Como é largamente conhecido na esfera da educação em ciências, as velhas estratégias de ensino como o quadro e giz/pincel, são insuficientes em assegurar que os discentes, realmente aprendam os conceitos científicos. Sabemos que o processo de ensino e aprendizagem é complexo, mutável no tempo, envolve múltiplos saberes e está longe de ser fácil.

Por essa razão temos a consciência de que o Ensino de Química deva ser trabalhado com o objetivo de despertar o interesse por conteúdos muitas vezes abstratos e aparentemente sem nenhuma relação com o dia-a-dia do aluno. Mas que como sujeitos da ação que somos, entender o outro é também compreender a sua matriz histórica e isso reflete diretamente no que quero construir em sala de aula juntamente com meus alunos.

Os próximos passos desta pesquisa, vislumbra estender esse olhar e reflexão para o educando em outros espaços, nesse caso considerando os espaços não formais. Uma vez que tais ambientes, oportunizam ainda mais tecer as relações entre os educandos e educadores.

\section{Referências}

Chassot, A (2002). Alfabetização Científica: questões e desafios para a educação. (2a ed.), Unijuí.

Carvalho, A. P. (1988) A formação do professor e a prática de ensino. Pioneira.

Espírito Santo (Estado). (2009) Secretaria da Educação. Conteúdo Básico Comum do Estado do Espírito Santo (CBC/ES). Vitória: SEDU, <http://sedu.es.gov.br/Media/sedu/pdf\%20e\%20Arquivos/Curr\%C3\%ADculo/SEDU_Curriculo_Basico_Escola_Estadual_(FINAL).pdf .

Freire, P. (1976). Ação cultural para a liberdade e outros escritos. Paz e Terra.

Galiazzi, M. C. (2003). Educar pela pesquisa: ambiente de formação de professores de ciências. Unijuí..

Gil-Perez, D., Montoro, I. F., Alis, J. C., Cachapuz, A., \& Praia, J. (2001). Para uma imagem não deformada do trabalho científico. Ciência \& Educação, 7(2) $125-153$.

Gomes, R. V. (2020). A História da Ciência no Ensino de Química: Um Estudo sobre a Tabela Periódica desenvolvido com futuros Professores. 159f. Dissertação (Mestrado em Ensino na Educação Básica). Universidade Federal do Espírito Santo, Centro Universitário do Norte do Estado do Espírito Santo, São Mateus.

Harres, J. B. S. (1999). Uma revisão de pesquisas nas concepções de professores sobre a natureza da ciência e suas implicações para o ensino. Investigações em Ensino de Ciências, 4, (3), 197-211.

Ludke, M. \& André, M. E. D. A. (2014). Pesquisa em educação: Abordagens Qualitativas. EPU

Maia, P. F, Justiz, R. (2008). Desenvolvimento de habilidades no ensino de ciências e o processo de avaliação: Análise da Coerência. Ciência \& Educação, 14 (3), $431-450$.

Machado, A. H. (2004). Aula de Química: discurso e conhecimento. Ed. Ijuí.

Mccomas, W. F., Clough, M. P., \& Nouri, N. (2019). Teaching aspects of the nature of science: a review of the literature with implications for effective NOS instruction. In W. F. McComas (Ed.), Nature of science in science instruction. Boston: Springer Academic (in press).

Maldaner, O. A. (2013). A formação inicial e continuada de professores de Química. Unijuí.

Maldaner, O. A. (2007). Currículo contextualizado na área de ciências da natureza e suas tecnologias: a situação de estudo. In: Zanon, L. B., Maldaner, O. A (Org.). Fundamentos e propostas de ensino de química para a educação básica no Brasil. Ijuí: Editora Unijuí.

Moreira, M. A. (2017). Teorias de Aprendizagem. EPU.

Moura, C., \& Guerra, A. (2016). História Cultural da Ciência: Um Caminho Possível para a Discussão sobre as Práticas Científicas no Ensino de Ciências? Revista Brasileira de Pesquisa em Educação em Ciências, 16 (3), 725-748. 
Research, Society and Development, v. 10, n. 6, e9610615577, 2021

(CC BY 4.0) | ISSN 2525-3409 | DOI: http://dx.doi.org/10.33448/rsd-v10i6.15577

Ramos, M. G., \& Moraes, R. (2011). A avaliação em Química: Contribuição aos processos de mediação de aprendizagem e de melhoria do ensino. In: Santos, W. L. P., Maldaner, O.A. (Org.). Ensino de Química em Foco. Unijuí.

Schnetzeler, R. P. (2002). Concepções e alertas sobre a Formação Continuada de Professores de Química. Química nova na escola, 16, 15-20.

Serpa, L. G., Machado, C. J., Nascimento, G. A. do. \& Almeida, A. R. (2021). Por uma educação a favor da páxis: ação, educação e cultura. Research, Scociety and Developmente, 10 (1), e54210112104. https://doi.org/10.33448/rsd-v10il.12104.

Silva, J. C. da \& Dutra, M. M. (2020) Ensino de Química no contexto da Educação Especial: Uma análise de artigos publicados na Revista Química Nova na Escola no período de 1995 a 2016. Revista Prática Docente, 5(1) 431-488.

Silva, J. C. S., Gomes, R. V., Carletto, B. M., \& Camata, J. G. (2021). A Química Encantada: O Uso de Jogos Didáticos como Ferramenta Pedagógica na Educação de Jovens e Adultos. In: Silveira, D. P., Silva, J. C. S., Scheffer, D. C. D. (Org.). Diálogos e Debates: Um Mosaico de Saberes na Contemporaneidade. Editora Ilustração: Cruz Alta, (1), 161-176.

Vygotsky, L. S. (2007). A formação social da mente: o desenvolvimento dos processos psicológicos superiores. Martins Fontes.

Vygotsky, L. S. (2000). Manuscrito de 1929. Educação \& Sociedade, 21(71), 21-44. 